\title{
CORRELATION OF ABNORMAL UTERINE BLEEDING CAUB] WITH THYROID PROFILE AND ENDOMETRIAL BIOPSY
}

\author{
Shraddha Koirala, ${ }^{1}$ Kricha Pande, ${ }^{1}$ Sama Shrestha ${ }^{2}$
}

${ }^{1}$ Department of Pathology, ${ }^{2}$ Department of Obstetrics and Gynecology, Nepal Medical College Teaching Hospital, Gokarneshwor-8, Kathmandu, Nepal

\section{ABSTRACT}

Abnormal uterine bleeding (AUB) is defined as any change in the frequency of menstruation, duration of flow or amount of loss. Menstrual disturbances and different endometrial pattern may accompany and precede thyroid dysfunction. The objective of the study was to correlate thyroid profile with endometrial biopsy in cases of AUB. This study was conducted on 74 patients who presented with AUB, had undergone TFT and endometrial biopsy/hysterectomy. Among 74 patients, thyroid disorders were identified in 26 patients. Maximum number of patients with AUB belonged to the category of hypothyroidism (27\%) and $8.1 \%$ of cases had hyperthyroidism. In the present study $29(39.1 \%)$ had proliferative endometrium, followed by secretory pattern in $21(28.4 \%)$ patients. Hormone induced changes was seen in $3(4.1 \%)$ patients. Disordered proliferative endometrium and endometrial hyperplasia was observed in 6 patients (8.1\%) each. Malignant lesion was not common and it comprised of only $1.4 \%$ cases. AUB is frequently seen in patients with thyroid dysfunction. Thyroid function test is a cost effective, easily available test and can detect a possibly curable cause of AUB and avoid unnecessary intervention like hormonal treatment and hysterectomy. AUB due to endometrial cause is an age related pathology. Histopathological examination of endometrial biopsy is a major diagnostic tool in evaluation of AUB. It helps the physician to plan therapy for successful management of AUB.

\section{KEYWORDS}

Abnormal uterine bleeding, Thyroid profile, Endometrial biopsy

Received on: September 12, 2021

Accepted for publication: November 05, 2021

\section{CORRESPONDING AUTHOR}

Dr. Shraddha Koirala, Lecturer,

Department of Pathology,

Nepal Medical College Teaching Hospital, Attarkhel,

Gokarneshwor-8, Kathmandu, Nepal,

Email: shraddhaa46@gmail.com

Orcid No: https://orcid.org/0000-0001-5155-8184

DOI: https://doi.org/10.3126/nmcj.v23i4.42227 


\section{INTRODUCTION}

The normal menstrual cycle length is 21-35 days with duration of menstrual blood flow of 2-7 days and blood loss of 20-80 ml. The upper limit of normal menstrual blood flow is 80 $\mathrm{ml}$ per menstruation. Any variation from the normal and the amount of loss more than 80 $\mathrm{ml}$ is considered Abnormal Uterine Bleeding (AUB). ${ }^{1}$ AUB may be defined as any variation from the normal menstrual cycle and includes changes not only in regularity and frequency of menses but also in duration of flow and in amount of blood loss. ${ }^{2}$

AUB includes Dysfunctional Uterine Bleeding (DUB) with no demonstrable pathology or those with demonstrable causes like polyp, leiomyoma, hyperplasia and carcinoma. Majority of these lesions can be diagnosed by endometrial biopsy. ${ }^{3}$

DUB refers to "AUB which is not due to demonstrable pelvic disease, complications of pregnancy or systemic disease". It is a diagnosis of exclusion. ${ }^{2}$ DUB is one of the commonest cause of AUB. ${ }^{1}$ Such bleeding is most often the result of endocrinologic dysfunction that inhibits normal ovulation. ${ }^{4}$

DUB can be primary, secondary and iatrogenic. Primary DUB is due to dysfunction arising in the hypothalamo-pitutary-ovarian axis or dysfunction in the endometrium itself. Secondary DUB is due to endocrinopathies, hematological, vascular disease and liver disorders. However, iatrogenic DUB is due to drugs, exogenous hormone administration, intrauterine contraceptive devices. ${ }^{5}$

AUB is a common problem imposing a significant impact on quality of life and financial burden in women of reproductive age group and it occurs in about $9-14 \%$ of women. About one third of hysterectomies are carried out for menstrual disorder alone and thyroid dysfunction is one of the important cause. Both hyper and hypothyroidism may present in menstrual disturbances. ${ }^{6}$

$9-30 \%$ of women of reproductive age suffer from menorrhagia, the prevalence increases with age and peaks just before menopause. As most of the cases are associated with anovulatory menstrual cycles, adolescent and peri-menopausal women are particularly vulnerable. $^{7}$ It is associated with various symptoms like heavier or prolonged menstrual flow with or without pain, passage of clots, weakness, lethargy associated with social embarrassment, significant alteration in lifestyle of individual and sexual compromise.
It adversely affect mood, energy/vitality, work productivity, social interactions, family life and sexual functioning. ${ }^{8}$

AUB affects up to a third of women of child bearing age and may reflect a serious underlying pathology. Menorrhagia affects 10$30 \%$ of menstruating women and may occur in peri-menopausal age group in up to $50 \%$ of women. ${ }^{9}$

Thyroid dysfunction causes a broad spectrum of reproductive disorders ranging from abnormal sexual development to menstrual irregularities, infertility and premature menopause. A relationship between the thyroid gland and the gonads is suggested by the more frequent occurrence of thyroid disorders in women and the common appearance of goiter during puberty, pregnancy and the menopause. ${ }^{10}$ Hypothyroidism usually causes menorrhagia and hyperthyroidism causes oligomenorrhoea. ${ }^{11}$

Endometrial biopsy is the usual investigation performed in AUB and it can help to determine the etiology and decide the management in these cases. ${ }^{12}$ Histopathological examination is the gold standard for studying the pattern of endometrium in various causes of AUB. The importance of studying the histological pattern of endometrium in AUB in different age group is to correctly diagnose the underlying etiology thus, helping in the management of disease. The most important objective in the postmenopausal age group is to rule out or to confirm malignancy. ${ }^{13,14}$

Menstrual disturbances and different endometrial pattern may accompany and precede thyroid dysfunction. Hence, this study is intended to correlate thyroid profile with endometrial biopsy in cases of AUB.

\section{MATERIALS AND METHODS}

A descriptive cross sectional study was conducted over a period of one year from May 2019 to April 2020 in the Department of Pathology, Nepal Medical College Teaching Hospital (NMCTH), Gokarneshwor-8, Kathmandu, Nepal. Patients attending the Gynecological outpatient department with abnormal uterine bleeding and undergoing TFT and endometrial biopsy/hysterectomy were included in the study. All women of reproductive age group who presented with menstrual irregularities like heavy menstrual bleeding, intermenstrual bleeding and breakthrough bleeding were included in the study. A complete history and TFT results was obtained from the 
patient file and filled in the proforma. AUB due to gestational causes like abortions, tubal pregnancies, molar pregnancies and rupture uterus were excluded. Pregnant patient and patient with bleeding disorders were also excluded from the study.

Endometrial samples obtained by biopsy, dilatation and curettage, fractional curettage and from the endometrium of hysterectomy specimens received in the Department of Pathology were studied/examined. Grossing of both endometrial biopsy and hysterectomy specimen were performed using standard protocol.

The grossed sections were processed using tissue processor (Yorko). Next day routine embedding, cutting followed by staining of the prepared slides with Hematoxylin and Eosin (H \& E) was done. The prepared slides was examined under binocular microscope (Nikon Eclipse E200). The pattern of endometrial histological changes were identified and classified according to age groups and thyroid status.

Informed written consent was taken from the participants of study. Ethical clearance was taken from the Institutional Review Committee (IRC) of NMCTH.

\section{RESULTS}

A total of 76 clinically considered cases of AUB subjected to endometrial biopsy/abdominal and vaginal hysterectomy were taken. Out of these 2 samples inadequate for opinion were excluded. Thus total of 74 cases of AUB was included in the analysis. Out of 74 cases 40 patients had undergone endometrial biopsy, 28 had undergone total abdominal hysterectomy and 6 had undergone vaginal hysterectomy. The age group of the patients in the study ranged from 26 to 62 years with the mean of 44.5 years.

Regarding age distribution of the patients, majority of the patients were in the age group of 36-45 years followed by age group 46-55years.

\begin{tabular}{|c|c|c|}
\hline Age groups (years) & No. of cases (n) & $\%$ \\
\hline $25-35$ & 8 & 10.8 \\
\hline $36-45$ & 35 & 47.3 \\
\hline $46-55$ & 28 & 37.8 \\
\hline$>56$ & 3 & 4.1 \\
\hline Total & 74 & 100 \\
\hline
\end{tabular}

Thyroid disorders were identified in 26 (35\%) patients. Maximum number of patients with AUB belonged to the category of hypothyroidism.

\begin{tabular}{|lcc|}
\hline \multicolumn{3}{|c|}{ Table 2: Distribution of patients according to } \\
thyroid dysfunction
\end{tabular}

\section{Table 3: Distribution of thyroid dysfunction} according to age groups

\begin{tabular}{|c|c|c|c|c|c|c|}
\hline \multirow{2}{*}{$\begin{array}{l}\text { Age } \\
\text { groups } \\
\text { (years) }\end{array}$} & \multicolumn{2}{|c|}{$\begin{array}{c}\text { Euthyroid } \\
\text { Total }=48\end{array}$} & \multicolumn{2}{|c|}{$\begin{array}{c}\text { Hypothyroic } \\
\text { Total }=20\end{array}$} & \multicolumn{2}{|c|}{$\begin{array}{c}\text { Hyperthyroid } \\
\text { Total }=6\end{array}$} \\
\hline & n & $\%$ & $\mathbf{n}$ & $\%$ & n & $\%$ \\
\hline $25-35$ & 6 & 12.5 & 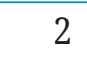 & 10 & 0 & 0 \\
\hline-45 & 24 & 50 & 10 & 50 & 2 & 33.3 \\
\hline $46-55$ & 18 & 37.5 & 7 & 35 & 2 & 33.3 \\
\hline$>56$ & 0 & 0 & 1 & 5 & 2 & 33.3 \\
\hline
\end{tabular}

Table 3 shows that thyroid dysfunction (hypo and hyperthyroidism) is common in age group 36-45 years followed by age group 46-55 years.

Table 4: Distribution of AUB cases according to histopathological pattern

\begin{tabular}{|lcc|}
\hline $\begin{array}{l}\text { Histopathological } \\
\text { pattern of AUB cases }\end{array}$ & $\begin{array}{c}\text { No. of cases } \\
\text { (n) }\end{array}$ & \% \\
\hline Proliferative pattern & 29 & 39.1 \\
Secretory pattern & 21 & 28.4 \\
Atrophic pattern & 2 & 2.7 \\
$\begin{array}{l}\text { Disordered proliferative } \\
\text { pattern (DPE) }\end{array}$ & 6 & 8.1 \\
Hormone induced changes & 3 & 4.1 \\
Endometrial polyp & 4 & 5.4 \\
Chronic endometritis & 2 & 2.7 \\
Endometrial hyperplasia & 6 & 8.1 \\
Endometrial carcinoma & 1 & 1.4 \\
\hline Total & 74 & 100 \\
\hline
\end{tabular}




\begin{tabular}{|c|c|c|c|c|c|c|c|c|c|c|}
\hline \multicolumn{11}{|l|}{$\begin{array}{l}\text { Endometrial } \\
\text { Pathology }\end{array}$} \\
\hline $\begin{array}{l}\text { Thyroid } \\
\text { status }\end{array}$ & 递 & 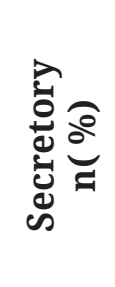 & 岂 & 崌异 & 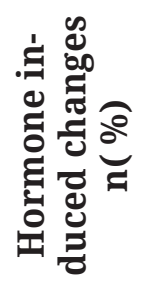 & 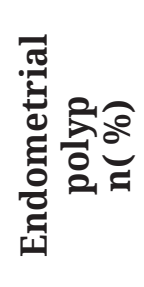 & 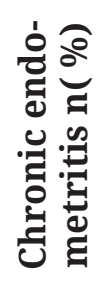 & 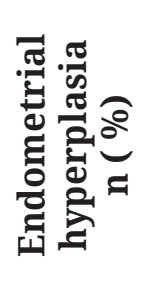 & 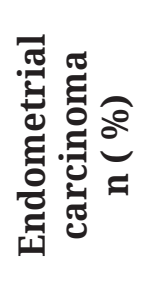 & 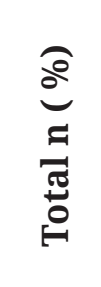 \\
\hline Hypothyroid & $\begin{array}{c}9 \\
(45)\end{array}$ & $\begin{array}{c}5 \\
(25)\end{array}$ & $\begin{array}{c}1 \\
(5)\end{array}$ & 0 & $\begin{array}{c}2 \\
(10)\end{array}$ & 0 & 0 & $\begin{array}{c}3 \\
(15)\end{array}$ & 0 & $\begin{array}{c}20 \\
(100)\end{array}$ \\
\hline Hyperthyroid & $\begin{array}{c}2 \\
(33.3)\end{array}$ & $\begin{array}{c}1 \\
(16.7)\end{array}$ & 0 & $\begin{array}{c}1 \\
(16.7)\end{array}$ & 0 & 0 & 0 & $\begin{array}{c}2 \\
(33.3)\end{array}$ & 0 & $\begin{array}{c}6 \\
(100)\end{array}$ \\
\hline Euthyroid & $\begin{array}{c}18 \\
(37.5)\end{array}$ & $\begin{array}{c}15 \\
(31.3)\end{array}$ & $\begin{array}{c}1 \\
(2.1)\end{array}$ & $\begin{array}{c}5 \\
(10.4)\end{array}$ & $\begin{array}{c}1 \\
(2.1)\end{array}$ & $\begin{array}{c}4 \\
(8.3)\end{array}$ & $\begin{array}{c}2 \\
(4.1)\end{array}$ & $\begin{array}{c}1 \\
(2.1)\end{array}$ & $\begin{array}{c}1 \\
(2.1)\end{array}$ & $\begin{array}{c}48 \\
(100)\end{array}$ \\
\hline Total & $\begin{array}{c}29 \\
(39.1)\end{array}$ & $\begin{array}{c}21 \\
(28.4)\end{array}$ & $\begin{array}{c}2 \\
(2.7)\end{array}$ & $\begin{array}{c}6 \\
(8.1)\end{array}$ & $\begin{array}{c}3 \\
(4.1)\end{array}$ & $\begin{array}{c}4 \\
(5.4)\end{array}$ & $\begin{array}{c}2 \\
(2.7)\end{array}$ & $\begin{array}{c}6 \\
(8.1)\end{array}$ & $\begin{array}{c}1 \\
(1.4)\end{array}$ & $\begin{array}{c}74 \\
(100)\end{array}$ \\
\hline
\end{tabular}

Histopathological examination showed normal cyclical pattern showing proliferative, secretory and atrophic pattern in 52 patients (70.2 \%) with proliferative pattern as the predominant finding in $29(39.1 \%)$ patients followed by secretory pattern in 21 (28.4) patients. Malignant lesions comprised of 1 $(1.4 \%)$ of the cases. It was a case of endometrial adenocarcinoma.

Most of the cases were euthyroid (65\%) followed by hypothyroid (27\%) and hyperthyroid (8\%). In hypothyroid patients $45 \%$ had proliferative endometrium and $25 \%$ had secretory endometrium. In hyperthyroid patients $33.3 \%$ had proliferative endometrium and $16.7 \%$ had secretory endometrium. Out of euthyroid patients $37.5 \%$ had proliferative endometrium and $31.3 \%$ had secretory endometrium.

\section{DISCUSSION}

AUB is one of the most commonly encountered conditions in females. Diagnosis of DUB is by exclusion. It is more common in fourth to fifth decades of life or in the perimenopausal age group. ${ }^{3}$ In the present study, majority of the AUB patients were in the age group of 3645 years $(47.3 \%)$ followed by $46-55$ years 28 $(37.8 \%)$. This is similar to the study done by Narula et al. ${ }^{15}$ and Pahwa et al. ${ }^{16}$ who observed $32.8 \%$ and $42 \%$ cases respectively in the age group 31-40 years. Rai et $a l^{17}$ and Subedi et al ${ }^{11}$ also observed that AUB was more common in the age group of 31-40 years.
In the present study, thyroid dysfunction was prevalent in $35 \%$ patients who presented with AUB, out of which $27 \%$ patients had hypothyroidism which was the most common thyroid dysfunction and $8 \%$ patients had hyperthyroidism, whereas $65 \%$ patients were euthyroid. In a study conducted by Rai et $a l^{17}$ thyroid dysfunction was seen in $24.9 \%$ patients, out of which $14.4 \%$ patients had subclinical hypothyroidism, $9.2 \%$ patients had overt hypothyroidism, $1.3 \%$ patients had hyperthyroidism and $75.2 \%$ patients were euthyroid. Similar findings were seen in several other studies. ${ }^{13,18,19}$

In the present study, thyroid dysfunction was common in age group 36-45 years followed by 46-55 years and in age group above 56 years respectively. This shows that thyroid dysfunction becomes more common as the age advances which is similar to the study conducted by Javed et $a l^{2}$ and Deshmukh et $a{ }^{20}$ In their study thyroid dysfunction was commonest in the age group of 31-40 years and 41-45 years respectively.

Most of the cases in this study showed normal physiological patterns and proliferative endometrium (39.1\%) was the commonest finding followed by secretory endometrium (28.4\%) and disordered proliferative endometrium (8.1\%). Gorla et al, Khanna et al, Doriaswami et al and Byna et al also reported prolifeartive endometrium as the commonest finding followed by secretory endometrium and disordered proliferative endometrium..$^{13,21-23}$ 
In the present study the occurance of endometrial hyperplasia was $8.1 \%$ which is similar to the study conducted by Bhat et $a l^{24}$ and Agrawal et $a l^{14}$. In their study occurance of endometrial hyperplasia was $9 \%$ and $9.6 \% \%$ respectively. However, Purandare et $a l^{25}$ found endometrial hyperplasia in $7 \%$ whereas Jairajapuri et $a l^{26}$ found $5.7 \%$ of endometrial hyperplasia. In contrast to all these, Iqbal et $a l^{27}$ reported $14.7 \%$ of endometrial hyperplasia.

In this study $5.4 \%$ cases were of endometrial polyp. This result was comparable to the study done by Bhat et $a l^{24}(4 \%)$ and Gorla et $a l^{13}(6.6 \%)$. In the present study $4.1 \%$ cases were of hormone induced changes which is slightly lower than the study conducted by Sharma et $a l^{4}(7 \%)$ and Dadania et $a l^{28}(10 \%)$. In this study atrophic endometrium was obsereved in only $2.7 \%$ of cases which correlates with other studies done by Nayak et $a l^{29}(2.5 \%)$. Khanna et $a l^{21}$ and Chattersal et $a l^{30}$ reported $3.8 \%$ and $3.4 \%$ of atrophic endometrium respectively. However, Shrama et $\mathrm{al}^{4}$ reported $10 \%$ cases of atrophic endometrium.

In this study $2.7 \%$ cases of chronic endometritis were observed, which is similar to the finding of Dadania et al $^{27}(2 \%)$ but in a study done by Gorla et $a l^{13}$ there were $1.1 \%$ of chronic endometritis.

The frequency of endometrial adenocarcinoma was low in the present study (1.4\%) which is similar to the study conducted by Khanna et $a l^{21}(1.2 \%)$, Chattarsal et al $30(1.8 \%)$ and Bhat et $a l^{24}(3 \%)$ respectively. However, Agrawal et $a l^{14}$ reported $4.8 \%$ cases of endometrial carcinoma.

In the present study, proliferative pattern was common in hypothyroid (45\%) as well as hyperthyroid $(33.3 \%)$ patients. Secretory pattern was seen in $25 \%$ of hypothyroid and
$16.7 \%$ of hyperthyroid patients respectively. Similarly, Sharma et $a l^{19}$ also reported proliferative pattern as common pattern in both hypothyroidism and hyperthyroidism (36.3\% and $42.48 \%$ respectively). Rani et $a l^{9}$ also reported proliferative pattern as the commonest pattern in patient with hypothyroidism (63.15\%) followed by secretory pattern $(26.31 \%)$.

Verma et $a l^{3}$ conducted a study among the 200 women and observed that $74.3 \%$ patients had proliferative endometrium, 26.3\% secretory endometrium, in hypothyroid patients and secretory endometrium in 2 (1\%) hyperthyroid patients.

In Conclusion, AUB is frequently associated with thyroid dysfunction. Any type of menstrual disorder should be considered as a possible presenting symptom of thyroid dysfunction as in majority of patients menstrual abnormality may precede other signs and symptoms and thyroid assessment should be done in all these cases. Thyroid function test is a cost effective, easily available test and can detect a possibly curable cause of AUB and avoid unnecessary intervention like hormonal treatment and hysterectomy.

Endometrial cause of AUB is age related pathology. Histopathological examination of endometrial biopsy is a major diagnostic tool in the evaluation of abnormal uterine bleeding and a specific diagnosis could help the physician to plan therapy for successful management of AUB.

\section{Conflict of interest: None}

Source of research fund: Funded by NMC Research Grant 2019 (approval no. 049075/076).

\section{REFERENCES}

1. Kayastha S. Study of endometrial tissue in dysfunctional uterine bleeding. Nepal Med Coll J 2013; 15: 27-30.

2. Ali J, Das KK, Konyak P. Study of relation of thyroid profile with abnormal uterine bleeding. Sch J App Med Sci 2015; 3: 2688-92.

3. Verma SK, Pal A, Jaswal S. A study of thyroid dysfunction in dysfunctional uterine bleeding. Int'l J Reprod Contracept Obstet Gynecol 2017; 6: 2035-9.

4. Sharma M, Khajuria R. Histopathological evaluation of endometrial curettings in perimenopausal women presenting with abnormal uterine bleeding (AUB). J Evid Based Med Health 2018; 5: 940-42.

5. KatuwalN,GurungGR,JhaA.Aclinicopathological study of dysfunctional uterine bleeding. J Pathol Nepal 2014; 4: 635-8.

6. Kattel P, Baral G. Thyroid function test in abnormal uterine bleeding. Nepal J Obstet Gynecol 2017; 2: 74-8.

7. Nepal N, Choudhary PK, Mainali N. Histopathological analysis of endometrial biopsies in dysfunctional uterine bleeding. $J$ Pathol Nepal 2016; 6: 910 -13. 
8. Rani AS, Rekha B, Reddy GA. Study of Hypothyroidism in women with abnormal uterine bleeding. J Dental Med Sci 2016; 15: 12-8.

9. Tiwari A, Kaur N, Jain S, Rai R, Jain SK. Histopathological study of endometrial biopsy specimens for abnormal uterine bleeding. $J$ Lumbini Med Coll 2016; 4: 72-6.

10. Jinger SK, Verma A, Dayma I, Talreja T. To study the thyroid profile in menstrual disorder at tertiary care hospital in northern western Rajasthan, India. Int'l J Res Med Sci 2017; 5: 22124.

11. Subedi S, Banerjee B, Manisha C. Thyroid disorders in women with dysfunctional uterine bleeding. J Pathol Nepal 2016; 6: 1018 -20.

12. Gupta A, Paitiri K, Gupta G, Gupta R, Khare P. Histopathological patterns in endometrial biopsy associated with abnormal uterine bleeding. Asian Pac J Health Sci 2018; 5: 31-6.

13. Gorla P, Sanapala S, Devi E, Atla BL, Rasaputra M. Histopathology of endometrium in abnormal uterine bleeding in correlation with thyroid profile and ultrasonography findings. Int'l J Res Med Sci 2016; 4: 1463-9.

14. Agarwal P, Garg R, Rai N, Prakash P. Abnormal uterine bleeding. J South Asian Feder Menopause Soc 2016; 4: 22-6.

15. Narula ER, Menstrual Irregularities. Jol Obstet Gynecol India 1967; 17:164.

16. Pahwa S, Gupta S, Kumar J. Thyroid dysfunction in dysfunctional uterine bleeding. J Adv Res Biol Sci 2013; 5: 78-83.

17. Rai A, Raina S. A study of prevalence of thyroid dysfunction in abnormal uterine bleeding. Int'l J Reprod Contracept Obstet Gynecol 2020; 9: 29059.

18. Singh S, Sahoo S, Das PC. A study of thyroid dysfunction in dysfunctional uterine bleeding. Int'l J Reprod Contracept Obstet Gynecol 2018; 7: 1002-6.

19. Sharma N, Sharma A. Thyroid profile in menstrual disorders. JK Sci 2012; 14: 14-7.

20. Deshmukh PY, Boricha BG, Pandey A. The association of thyroid disorders with abnormal uterine bleeding. Int'l J Reprod Contracept Obstet Gynecol 2015; 4: 701-8.
21. Khanna K, Sudha V. A reterospective study on the endometrial biopsy of AUB correlated to thyroid abnormalities and endometrial thickness. $J$ Diagn Pathol Oncol 2019; 4: 226-29.

22. Doraiswami S. Study of endometrial pathology in abnormal uterine bleeding. J Obstet Gynaecol India 2011; 61: 426-30.

23. Byna P, Siddula S, Kolli S, Shaik MV. Histopathological correlation of abnormal uterine bleeding in perimenopausal women. Int'l J Reprod Contracept Obstet Gynecol 2015; 4: 1875-83.

24. Bhat R, Sudhamani S, Roplekar P. Histological study of endometrium in abnormal uterine bleeding in perimenopausal and postmenopausal women. J Sci Soc 2019; 46; 95-8.

25. Purandare S, Jhalam L. Pathological picture in hysterectomy done for abnormal uterine bleeding. J Obstet Gynecol India 1993; 43: 418-21.

26. Jairajpuri ZS, Rana S, Jetley S. Atypical uterine bleeding Histopathological audit of endometrium - A study of 638 cases. Al Ameen J Med Sci 2013; 6: 21-28.

27. Iqbal MB, Kambale T, Khandelwal A, Banerjee B. Spectrum of Endometrial lesions in patients presenting with abnormal uterine bleeding. Indian J Pathol Oncol 2018; 5: 587-91.

28. Dadhania B, Dhruva G, Agravat A. Histopathological study of endometrium in dysfunctional uterine bleeding. Int'l J Res Med 2013; 2: 20-4.

29. Nayak AK, Hazra K, Jain MK. Clinico-Pathological Evaluation of Dysfunctional Uterine Bleeding. Int'l J Contem Med Res 2017; 4: 920-24.

30. Chhatrasal C, Shelgaonkar G, Kulkarni CV, Ghanghoria S, Yadav A, Aggarwal P. Evaluation of endometrial histopathological patterns in abnormal uterine bleeding: A study of 1545 cases. Int'l J Med Sci Public Health 2017; 6: 124043. 